\title{
Inquiry Base Learning Model in Electrical Machine Learning
}

\author{
Marwan Affandi ${ }^{1)}$, Adi Sutopo ${ }^{2)}$, Mustamam ${ }^{3)}$ \\ Universitas Negeri Medan, Indoensia ${ }^{1,2,3}$ \\ marwanafandi@unimed.ac.id
}

\begin{abstract}
This paper aims to discuss the importance of electrical machine modules in the learning system in the Department of Electrical Engineering. Mastery of electrical machinery courses is part of the main competencies that must be mastered by Electrical Engineering students. This is because electric engines are a major part of the electric power system, namely in the generation, distribution and use of electrical energy. The mastery of electrical machine competence is not only theoretically (cognitive) but must be accompanied by the ability to operate and maintain its operations. The mastery of the competence of the electric machine can be achieved through practical activities and analysis of the results of the practice carried out carefully and comprehensively. Practical and analytical activities can be optimized if students are active and try to find solutions to problems independently through inquiry learning models.
\end{abstract}

Keywords: electrical machines, electrical machine competencies, inquiry models

\section{Introduction}

The mastery of electrical machinery in electrical engineering curriculum both for electrical engineering (non-educational) and electrical engineering education is included in core competencies. This is because electrical machines are a major part of the power system of the generation, distribution and consumption of electrical energy. Electrical machines consist of electrical generators, electric motors as well as transformers. Based on the kind of wave motors and generators consist of direct current and alternating current. Transformers consist of power transformers and measuring transformers.

Electrical machine function in electrical energy generation is generating electrical energy in the form of generators. The electricity generated by the generator needs to be channeled to consumers that are up to hundreds of kilometers, so it requires an electrical machine to raise its electricity voltage to be more effective and efficient with the transformer. Meanwhile, consumers (users) consisting of industries, agencies and the general public use a lot of electric motors to move mechanical equipment to produce mechanical energy (rotary) such as; Fan, AC, water pump, lathes, scrap and so forth.

Mastery of electrical machine competence is the main for all electrical engineering students, because of the importance of electrical machines in human life and industry. Competency mastery of electrical machine theoretically and practically can be achieved if in the process of learning to teach electrical machine material using model and learning approach in accordance with the characteristics of electrical machine material. It also takes adequate tools and materials as a learning resource. 
The source of electrical machine learning can be text book, Journal, Report of research results, electrical machine equipment and materials. These learning resources need to be organized to form an integrated learning model, making it easier for lecturers and students in teaching and learning activities to achieve the learning outcomes expected by the industry and society.

Electric machine based on its direction source is divided into two namely DC electrical machine and AC. The AC power machine consists of DC Generator and DC Motor with same construction, so that DC generator can be converted into DC motor and vice versa depending on requirement. The difference is that the generators generate electrical power and require a starting drive, while DC Motors require electrical power to be converted into motion energy. DC machine IE generator or motor consist of generators/DC motors series, generators/motor shunt and generators/motor components.

AC Power Machine based on its use consists of generators, motors and transformers. The AC generator consists of synchronous generators and Asynkron generators. Based on the façade consists of 1 phase and 3 phases. AC motor is divided into two of the motor Syncrone and motor Asyncron. The Asyncron motor is based on a 1-phase and 3-phase motor. The 3-phase Asynchronous motor consists of a cage rotor motor and a puncte rotor motor. While the 1 st phase Asynchronous motor consists of various types of motors namely series motor, shaded pole, motor start capacitor, motor running capacitor, and motor repulsion.

The transformer is an electric machine that has no moving parts or is called a static electrical machine, but has the same working principle with other electrical machines that is by electromagnetic induction. Based on its fasts the transformer consists of 1 phase transformer and three phase transformer. Based on its roll consists of two-coil transformers and a single-coil transformer (auto transformer). Based on its use consists of power transformers and measuring transformers. Based on the tension changes are divided into two namely the transformer step up and transformer step down. The function of the transformer is to move the electrical power from one circuit to another by not reducing the electrical power except for the resulting losses on the transformer.

The electrical machine in its operation cannot stand alone but it requires a measuring device and other auxiliary materials. Assistive devices can serve as safety and ease of operation. AIDS serve as safeguards such as over load relay, $\mathrm{MCB}$, while auxiliary equipment for operation function consist of connecting cables, magnetic switch and mechanical switch. In addition to be able to understand the character (characteristic) Kettle machine requires various measuring instruments such as volt meter, ampere meter, cos Q meter, frequency meter and watt meter.

The Trainer module is developed based on the need for electrical practice as a student guideline in the activities at the lab/workshop. Electrical Machine module contains guidelines in implementing the electrical machine practice. By using electrical machine tools in the laboratory of Energy Conversion Department of Electrical Engineering, materials and tools required include: Electrical machines, magnetic contactors, push buttons, relays, safety fuse, and measuring instruments. All materials and tools are assembled in a trainer that allows students to carry out various electrical machine experiments.

Research and experiments that students can do include: characteristics of electrical machines, electrical machine operating systems and other research-related electrical machines. Designing the electric engine trainer module with the inquiry approach model is the safety factor of the tool, material and use of attention. The inquiry Model to be used in Electrical machine module is Confirmation inquiry [1]. Confirmation inquiry is deemed appropriate for the development of electrical machine module because of its purpose to confirm for further 
knowledge, in this case the knowledge of electrical machine. The purpose of the Electrical machine module is to provide direction to the students in order to apply their theoretical knowledge in the form of direct practice development. Development of Electrical Machine trainer module designed to adjust availability tools and materials in electrical machine laboratory.

Electric machine Trainer module with Confirmation Inquiry model provides extensive opportunity on students to develop electrical machine knowledge. Model Confirmation Inquiry in Electrical machine module is expected to encourage students of electrical engineering active, creative, and innovative. In addition to using the Model Confirmation Inquiry students are able to elaborate various supporting knowledge so as to make the knowledge of electrical engineering students become comprehensive. Inquiry-based learning provides opportunities for students to: develop skills they will need all their lives, learn to cope with problems that may not have clear solutions, deal with changes and challenges to understandings and shape their search for solutions, Now and in the future [1].

\section{Method of Inquiry Learning Model in Practice Learning}

The mastery of knowledge and technology of electrical machinery for students is not limited in cognitive mastery but also psychomotor mastery. The importance of psychomotor mastery is not to be released from the knowledge ability of electrical machines. The ability of psychomotor in electrical machines is the ability to operate electrical machines in accordance with the prevailing operational standards and electrical engine characteristics, so that the use of electric machines becomes safe, effective and efficient.

The learning of electrical machines for students is very important because all industries are unable to escape the needs of electrical machines in their production. Similarly, government and private agencies and households are currently unable to break away from electrical machines, albeit with relatively small power values. The application of the enquiries model is done with the enquiries guided system. The suppression of the Inquenous model is emphasized on the student's efforts in planning the wiring in engine operation, operating, and measuring[6]. The mentoring is done as an assessment and feedback to what is planned and practiced by the students so that when an error occurs it can be repaired immediately. It is important always carried out supervision in the implementation of the practice, because in addition to harmful students can also lead to damage to the electrical machine used in practice.

There are 4 stages in enquiries Learning model: The first phase of inquiry-based learning is one characterized by interaction, Clarification by analyzing data, identifying and clarifying misconceptions, and otherwise "getting a feel" for the scale, nature, and possibility of selected topics of inquiry, Questioning The Questioning phase is a critical phase of The inquiry-based learning process, if for no other reason than misunderstandings, lack of organization, uneven confidence, or an inability to see The "big picture" surface here more clearly than other Phases, and Design At This final stage of the inquiry-based learning process, learners are focused on design $[2,5]$.

Meanwhile, the stage in the implementing of the Inquiry model [4]: Phases the new inquiry-based learning is Orientation focuses on stimulating interest and curiosity in relation to the problem at hand. Conceptualization is a process of understanding a concept or concepts belonging to the stated problem. It is divided into two sub-phases, Questioning and Hypothesis Generation., Investigation is the phase where curiosity is turned into action in order to respond 
to the stated research questions or hypotheses, Conclusion is the phase in which the basic conclusions of A study are stated, Discussion contains the sub-phases of Communication and Reflection. Communication can be seen as an external process where students present and communicate their findings and conclusions to others, and receive feedback and comments from other.

\section{Analysis, Result and Discussion}

The inquenvious approach in the module only gives an overview of how students issue ideas or develop ideas that have to be applied in application settings and understanding the characteristics of electrical machines based on science that already owned about the electric machine. Based on this, students can pour development ideas and develop a minimal psychomotor ability at articulation level such as able to build and expand the control circuit of the electric generator motor and formulate transformer magnitudes of its characteristic trials. Some have emphasized the active nature of student involvement, associating inquiry with "hands-on" learning and experiential or activity-based instruction. Others have linked inquiry with a discovery approach or with development of process skills associated with "The scientific method." Though these various concepts are interrelated, inquiry-oriented instruction is not synonymous with any of them. [2,3]

Enquiries approach encourages students to integrate the science that is owned as a basis in developing and building a series of electrical machines for various needs. This is considering the electrical machine cannot stand alone in its operation [7]. Students should be able to relate between alternating current electric circuits that talk about a balanced circuit, a series of triangular stars. In addition to the capability of electrical installations such as arranging a true and safer power system as a base in the operation of electrical machines. This can be done when learning using the project method. The intended project is the duties given to the students in the form of development themes in the application and operation of electric machine operations

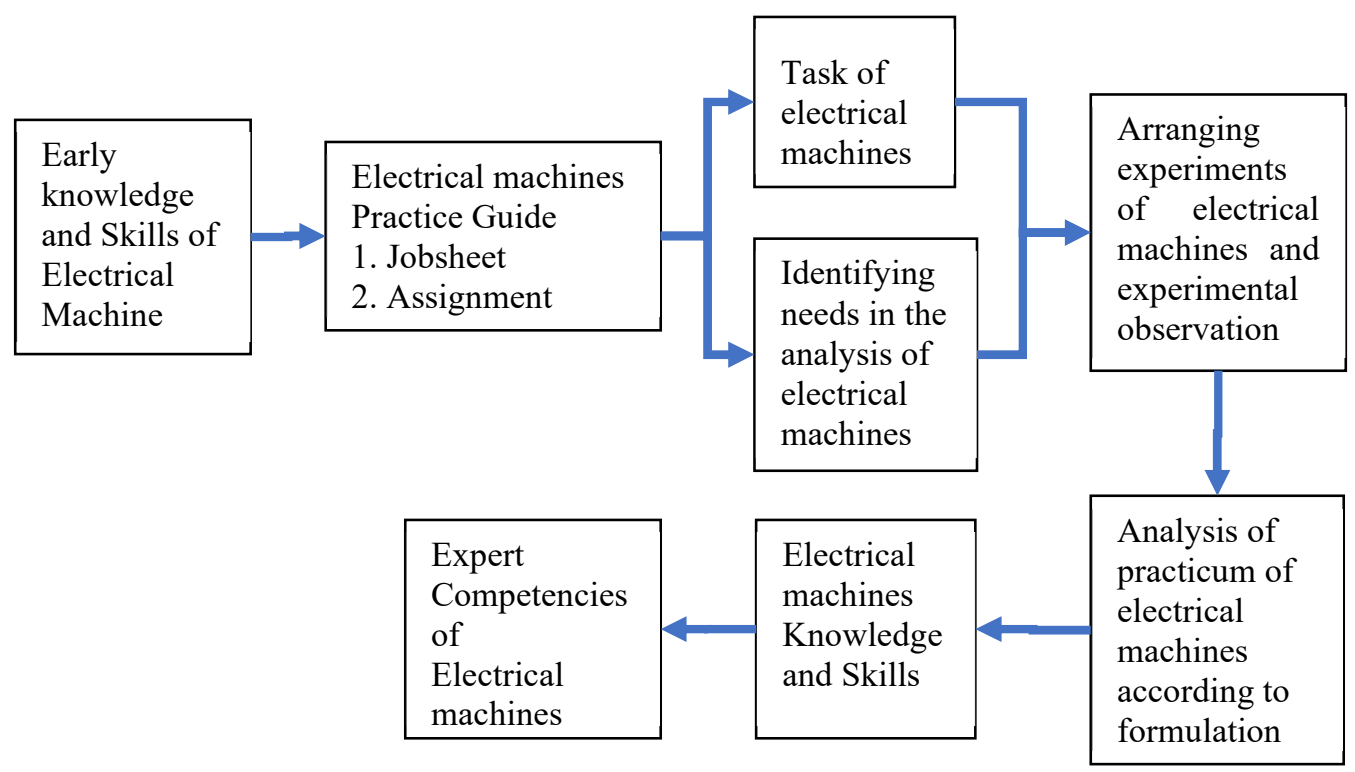

Fig 1. Knowledge and Skills of Electrical Machine 


\section{Conclusion}

1. The mastery of electric machines is a major competency that must be possessed by electrical engineering students because industry, government/private agencies, the public cannot be separated from the use of electrical machines

2. Mastery of electrical machine competence comprehensively achieved if the students in the Learning conduct analysis activities conducted theoretically and practically

3. Deeper mastery of electrical machine competence can be implemented with enquiries learning methods that encourage students to be active, creative and innovative in the operation and security of electrical machinery

\section{References}

[1] Alberta Learning. Inquiry-based Learning. Taken from http://www.learnalberta.ca/content/kes/pdf/or_ws_tea_inst_02_inqbased.pdf (2004).

[2] Terry Heick. 4 Phases Of Inquiry-Based Learning: A Guide For Teachers. Taken from https://www.teachthought.com/pedagogy/4-phases-inquiry-based-learning-guideteachers/ (2019).

[3] Haury, David L. Teaching Science through Inquiry. Taken from https://www.ericdigests.org/1993/inquiry.htm (1993).

[4] Margus Pedaste et. al. Phases of inquiry-based learning: Definitions and theinquiry cycle. https://reader.elsevier.com/reader/sd/pii/ (2015).

[5] Md lah Al Mamun, Gwendolyn Lawrie, Tony Wright. Instructional design of scaffolded online learning modules for self-directed and inquiry-based learning environments. Taken from https://www.sciencedirect.com/science/article/abs/pii/S0360131519302489 (2019).

[6] Somov, A. Wildfire safety with wireless sensor networks. EAI Endorsed Transactions on Ambient Systems (2011).

[7] Motaz, A. Start programming using Object Pascal. Legally Free Computer Books, US (2013). 